\title{
Phagocytosis and Killing of Staphylococcus aureus by Human Neutrophils
}

\author{
Thea Lu Adeline R. Porter Adam D. Kennedy Scott D. Kobayashi \\ Frank R. DeLeo \\ Laboratory of Human Bacterial Pathogenesis, Rocky Mountain Laboratories, National Institute of Allergy and \\ Infectious Diseases, National Institutes of Health, Hamilton, Mont., USA
}

\section{Key Words}

Neutrophils · Phagocytosis · Staphylococcus aureus

\begin{abstract}
Neutrophils are essential for host defense against Staphylococcus aureus infections. Although significant progress has been made, our understanding of neutrophil interactions with $S$. aureus remains incomplete. To provide a more comprehensive view of this process, we investigated phagocytosis and killing of $S$. aureus by human neutrophils using varied assay conditions in vitro. A greater percentage of bacteria were internalized by adherent neutrophils compared to those in suspension, and, unexpectedly, uptake of S. aureus by adherent neutrophils occurred efficiently in the absence of opsonins. An antibody specific for S. aureus promoted uptake of unopsonized bacteria in suspension, but had little or no capacity to enhance phagocytosis of $S$. aureus opsonized with normal human serum or by adherent neutrophils. Collectively, these results indicate that assay conditions can have a significant influence on the phagocytosis and killing of $S$. aureus by neutrophils. More importantly, the results suggest a vaccine approach directed to enhance opsonophagocytosis alone is not sufficient to promote increased killing of S. aureus by human neutrophils. With the emer-
\end{abstract}

gence and reemergence of antibiotic-resistant microorganisms, establishing parameters that are optimal for studying neutrophil-S. aureus interactions will pave the way towards developing immune-directed strategies for anti-staphylococcal therapies.

(c) 2014 S. Karger AG, Basel

\section{Introduction}

Polymorphonuclear leukocytes (PMNs) or neutrophils are the most prominent cellular component of innate immunity and are recruited rapidly to the site of infection by host- and microbe-derived chemotactic factors. Phagocytosis is typically aided by complement and antibody (Ab) receptors present on the cell surface [1]. Following phagocytosis, microbes are exposed to reactive oxygen species and antimicrobial peptides, which effectively kill and digest most microorganisms [2]. Indeed, it is well known that neutrophils are essential for host defense against Staphylococcus aureus infections [3]. On the other hand, S. aureus is a prominent cause of community bacterial infections worldwide, and, thus, the pathogen has significant capacity to circumvent killing by neutrophils and other phagocytic cells [4]. This immune evasion

\section{KARGER}

\section{(C) 2014 S. Karger AG, Basel}

$1662-811 X / 14 / 0065-0639 \$ 39.50 / 0$

E-Mail karger@karger.com

www.karger.com/jin
Dr. Frank R. DeLeo

Rocky Mountain Laboratories, NIAID/NIH

903 South 4th Street

Hamilton, MT 59840 (USA)

E-Mail fdeleo@ niaid.nih.gov 
attribute is confounded by the high prevalence of antibiotic resistance in S. aureus [e.g., as with methicillin-resistant S. aureus (MRSA)], a major problem for treatment of infections. Therefore, enhanced understanding of neutrophil-S. aureus interactions is important for the development of immune-based therapies designed to prevent or moderate $S$. aureus infections [5].

Previous studies, some performed many years ago [6], investigated the contribution of host serum $\mathrm{Ab}$ and complement to neutrophil phagocytosis of S. aureus. Phagocytosis of $S$. aureus by neutrophils can occur in the absence of these opsonins [7-10], but the process is more efficient with opsonized microorganisms [11]. Therefore, it seems logical that past efforts to develop a vaccine against $S$. aureus have largely been directed to enhance opsonophagocytosis $[12,13]$. These vaccine candidates promote opsonophagocytosis in vitro and confer protection in animal infection models, but human clinical trials utilizing these molecules have met previously with little or no success [14]. One possible explanation for this disconnect (that between the experimental systems and human clinical trials) is that opsonophagocytosis assays and mouse infection models do not faithfully mimic conditions in humans. Notably, the mouse is naive and lacks specific $\mathrm{Ab}$ to $S$. aureus. Therefore, previous vaccine approaches directed to enhance opsonophagocytosis work well in the mouse because it lacks preexisting opsonic $\mathrm{Ab}$. By comparison, all humans have specific (opsonic) Ab to $S$. aureus and/or generate an immune response to $S$. aureus because of previous exposure. Thus, addition of additional opsonic $\mathrm{Ab}$ in human neutrophil assays in vitro is not likely to have a major effect on opsonophagocytosis, although it is possible that uptake is influenced by assay conditions. A systematic approach to testing the impact of assay conditions in vitro on human neutrophil phagocytosis of S. aureus has not been conducted. Here, we tested the hypothesis that opsonophagocytosis and opsonophagocytic killing of $S$. aureus by human neutrophils in vitro are highly influenced by assay conditions. Furthermore, we investigated whether the ability of normal human sera to promote opsonophagocytosis can be enhanced by addition of rabbit $\mathrm{Ab}$ specific for $S$. aureus.

\section{Methods}

\section{Bacterial Strain and Culture}

S. aureus strain LAC (a pulsed-field type USA300 strain) [15, 16] was grown overnight in trypticase soy broth (BD Biosciences). Overnight cultures of $S$. aureus were diluted 1:200 in fresh trypticase soy broth. S. aureus were cultured at $37^{\circ} \mathrm{C}$ with shaking $(220$ r.p.m.) to mid-exponential $\left(\mathrm{OD}_{600} \approx 0.7\right)$ or stationary $\left(\mathrm{OD}_{600} \approx\right.$ 2.0) phase of growth, at which time they were washed with phosphate-buffered saline (PBS). Bacteria were opsonized using 1, 3, or $50 \%$ autologous human serum or $50 \%$ pooled human serum (pooled from 5 blood donors) by incubating at $37^{\circ} \mathrm{C}$ for $30 \mathrm{~min}$ with gentle agitation, washed twice with PBS, and resuspended in RPMI 1640 medium (Invitrogen) buffered with $10 \mathrm{mM}$ HEPES (RPMI/H, pH 7.2). Freeze-thawed serum was prepared by freezing fresh serum aliquots at $-80^{\circ} \mathrm{C}$ and subsequently thawing at room temperature. Serum-opsonized bacteria were used immediately for experiments.

\section{Ab Production and Purification}

S. aureus strains MW2 [17], LAC [15, 16], MRSA252 [18], Newman [19], COL [20], and N315 [21] were grown to mid-exponential $\left(\mathrm{OD}_{600} \approx 0.7\right)$ and early stationary $\left(\mathrm{OD}_{600} \approx 2.0\right)$ phases of growth. Colony-forming units (CFUs; $\left.1.7 \times 10^{8}\right)$ of each strain were heat-killed at $95^{\circ} \mathrm{C}$ for $5 \mathrm{~min}$. All strains were combined and washed once with PBS. Killed bacteria were suspended in $2.5 \mathrm{ml}$ PBS and mixed 1:1 with complete Freund's adjuvant and emulsified. New Zealand white female rabbits $(n=6)$ were given subcutaneous injections of the $S$. aureus cocktail containing $10^{9}$ killed bacteria in Freund's adjuvant every 4 weeks for 20 weeks. Serum was collected 2 weeks after the first boost ( 6 weeks after the first immunization) and then every 4 weeks thereafter. Twenty-two weeks following the first immunization, sera were harvested and pooled, and used for the current studies. Ab was purified using the Pearl IgG purification kit (G Biosciences). The anti-S. aureus polyclonal rabbit antiserum ( $\alpha S$. aureus), or purified $\mathrm{Ab}$, recognized multiple surface $S$. aureus proteins by immunoblot analysis and bound intact $S$. aureus as assessed by immunofluorescence microscopy (data not shown). Production of Ab in rabbits was approved by the Institutional Animal Care and Use Committee, Rocky Mountain Laboratories, National Institute of Allergy and Infectious Diseases. The studies conformed to the guidelines of the National Institutes of Health.

\section{Isolation of Human PMNs}

Human neutrophils were isolated from heparinized venous blood of healthy donors using dextran sedimentation and FicollHypaque gradient centrifugation as described previously [22]. This work was performed in accordance with a protocol approved by the Institutional Review Board for Human Subjects, National Institute of Allergy and Infectious Diseases. All human subjects gave informed consent prior to participation in the study. Purity of PMN preparations and cell viability were determined by flow cytometry (FACSCalibur, BD Biosciences) as described previously [22]. Using this method, cell preparations typically contain approximately $98-99 \%$ granulocytes - primarily neutrophils with 2-5\% eosinophils.

\section{Binding (Association) of S. aureus with Human PMNs}

$S$. aureus strain LAC was cultured to mid-exponential phase of growth and suspended in RPMI/H to $10^{8} \mathrm{CFU} / \mathrm{ml} ; 100 \mu \mathrm{l}$ of bacteria were combined with $900 \mu$ human heparinized blood in a $1.5-\mathrm{ml}$ tube and rotated gently at $37^{\circ} \mathrm{C}$ for the indicated time points. At desired times, samples were prepared on microscope slides and stained with Wright-Giemsa. To determine the association of bacteria with isolated adherent neutrophils, neutrophils were allowed to adhere to serum-coated coverslips for $15 \mathrm{~min}$ at 
room temperature. Bacteria were combined with neutrophils at a 1:1 CFU:PMN ratio and centrifuged at $524 \mathrm{~g}$ for $8 \mathrm{~min}$ at $4^{\circ} \mathrm{C}$. Samples were then incubated at $37^{\circ} \mathrm{C}$ for the indicated times, at which point coverslips were washed with PBS to remove unbound bacteria, and cells were stained with Wright-Giemsa and evaluated as described below. Alternatively, neutrophils and bacteria (1:1 CFU:PMN ratio) were combined in a $1.5-\mathrm{ml}$ tube and rotated gently at $37^{\circ} \mathrm{C}$ for the indicated time points. To remove the majority of unbound bacteria, supernatant was removed after centrifugation $\left(110 \mathrm{~g}, 4^{\circ} \mathrm{C}, 5 \mathrm{~min}\right)$. The resulting pellet containing bacteriaassociated neutrophils was resuspended in RPMI/H. Slides were prepared from cell pellets using a CytoSpin (Thermo Shandon CytoSpin 4) and they were subsequently stained with Wright-Giemsa. For assays with adherent PMNs or those in suspension, 50 cells per time point per treatment from random fields were scored for associated bacteria by using a light microscope.

\section{Phagocytosis of S. aureus by Human PMNs}

For assays with adherent PMNs, synchronized phagocytosis was performed as described previously [22-24]. In general, bacteria were washed in PBS and opsonized with 1,3 , or $50 \%$ autologous or pooled normal human serum as indicated at $37^{\circ} \mathrm{C}$ for $30 \mathrm{~min}$. Bacteria were washed with PBS and resuspended at the desired concentration in RPMI/H. Human neutrophils were aliquoted at the desired concentration in tissue culture plates precoated with normal human serum to prevent PMN activation. Neutrophils were allowed to adhere to the assay plate for $15 \mathrm{~min}$ at room temperature before addition of bacteria. Bacteria were added to the desired wells and assay plates were then centrifuged at $524 \mathrm{~g}$ for $8 \mathrm{~min}$ and $4^{\circ} \mathrm{C}$ to synchronize phagocytosis.

For assays with PMNs in suspension, human neutrophils and bacteria were combined in $1.5-\mathrm{ml}$ tubes and incubated at $37^{\circ} \mathrm{C}$ for up to $1 \mathrm{~h}$ with gentle rotation. At each time point, the contents of the tubes were transferred to plates containing coverslips and centrifuged at $524 \mathrm{~g}$ for $8 \mathrm{~min}$ at $4^{\circ} \mathrm{C}$. A ratio of 1 or $10 \mathrm{CFU}$ per PMN was used for experiments as indicated. PMNs were allowed to ingest $S$. aureus for the indicated times at $37^{\circ} \mathrm{C}$.

\section{Bactericidal Activity Assay}

For measurement of $S$. aureus survival after phagocytic interaction with adherent neutrophils, opsonized or unopsonized bacteria were combined with PMN at a ratio of 1:1 or 10:1 (CFU:PMN ratio) as indicated in 96-well flat-bottom microtiter plates (precoated with human serum and then washed extensively). Plates were centrifuged at $456 \mathrm{~g}$ for $7 \mathrm{~min}$ to synchronize phagocytosis, and samples were incubated at $37^{\circ} \mathrm{C}$ for up to $120 \mathrm{~min}$ as indicated. For measurement of $S$. aureus survival after interaction with neutrophils in suspension, PMNs in RPMI/H were combined with opsonized or unopsonized bacteria and incubated at $37^{\circ} \mathrm{C}$ for up to $120 \mathrm{~min}$ with gentle rotation. At the desired time points, saponin ( $22 \mu \mathrm{l}$ of a $1 \%$ solution, $0.1 \%$ final concentration) was added to each well or tube, the contents were mixed, and the plates or tubes were incubated on ice for $15 \mathrm{~min}$. Bacteria were subsequently passaged through a 25-gauge blunt-end needle (to disperse cell clumps) and plated on LB agar.

Surviving bacteria were enumerated the following day. Percent survival was calculated by comparing the numbers of surviving bacteria to those at $\mathrm{t}=0$ with the equation: $\left(\mathrm{CFU}_{\mathrm{PMN}+}\right.$ at $t / \mathrm{CFU}_{\mathrm{PMN}-}$ at $\left.t_{0}\right) \times 100$.

Phagocytosis and Killing of S. aureus by Human Neutrophils

\section{Immunofluorescence Microscopy}

Coverslips were washed with nitric acid, flamed with ethanol, and coated with $100 \%$ normal human serum in 24 -well tissue culture plates for $1 \mathrm{~h}$. Coverslips were washed twice with PBS and $3 \times$ $10^{5}$ PMNs were centrifuged (456 g) onto coverslips to facilitate adherence. Cells were fixed in $4 \%$ paraformaldehyde for $30 \mathrm{~min}$ on ice, washed three times in PBS, and incubated in blocking buffer (5\% goat serum in PBS) for $30 \mathrm{~min}$ at room temperature.

To stain uningested bacteria, PMN were incubated with a 1:100 dilution of $\alpha S$. aureus (described above) for $1 \mathrm{~h}$ at room temperature. Cells were subsequently washed three times with blocking buffer and stained with AlexaFluor 594 conjugated to goat antirabbit Ab (Molecular Probes, Life Technologies No. A11012) for 1 $\mathrm{h}$ at room temperature. After three washes in PBS, cells were fixed and permeabilized with 1:1 methanol:acetone for $10 \mathrm{~min}$ at $-20^{\circ} \mathrm{C}$. After three more washes in PBS, PMNs were incubated with aS. aureus (1:100 dilution) in blocking buffer for $1 \mathrm{~h}$ at room temperature. Cells were subsequently washed three times with blocking buffer and counterstained with AlexaFluor 488 conjugated to goat anti-rabbit Ab (Molecular Probes, Life Technologies No. A11008) for $1 \mathrm{~h}$ at room temperature. Phagocytosis for each condition was scored on a fluorescence microscope by counting bacteria associated with 50 PMNs from random fields of view. Percent internalized bacteria were determined using the following equation: [(bacteria $_{\text {green }}-$ bacteria $\left._{\text {red }}\right) /$ bacteria $\left._{\text {green }}\right] \times 100=$ bacteria $_{\text {internalized }}$.

To quantify CD63-positive phagosomes, PMNs were fixed with $300 \mu \mathrm{l} \%$ paraformaldehyde on ice for $30 \mathrm{~min}$ and permeabilized with 1:1 methanol:acetone for $10 \mathrm{~min}$ at $-20^{\circ} \mathrm{C}$. PMN were incubated subsequently for $1 \mathrm{~h}$ at room temperature with a 1:1,000 dilution of mouse anti-human CD63 (BD Pharmingen). After three washes in blocking buffer, cells were stained with AlexaFluor 488 goat anti-mouse Ab (1:1,000 dilution; Molecular Probes, Life Technologies). PMNs were stained with 4',6-diamidino-2-phenylindole (300 nM in PBS, Molecular Probes, Life Technologies) prior to mounting coverslips onto slides. PMNs were scored for CD63positive phagosomes by counting 50 cells from random fields.

\section{Statistical Analyses}

Five independent experiments were performed for each assay. Data were evaluated using one-way analysis of variance and Tukey's or Dunnett's post hoc test as indicated (GraphPad Prism 5; GraphPad Software).

\section{Results}

\section{Factors or Conditions That Influence Phagocytosis of}

\section{S. aureus}

To better understand the factors or conditions in vitro that are optimal for phagocytosis of $S$. aureus by human neutrophils, we tested the impact of the bacteria/PMN ratio, $S$. aureus growth phase, freezing/thawing of human serum used for opsonization, opsonization with autologous versus pooled human serum, and assays with neutrophils in suspension versus those that are adherent on neutrophil phagocytosis (fig. 1). Although previous studies reported conditions that can impact neutrophil phago- 


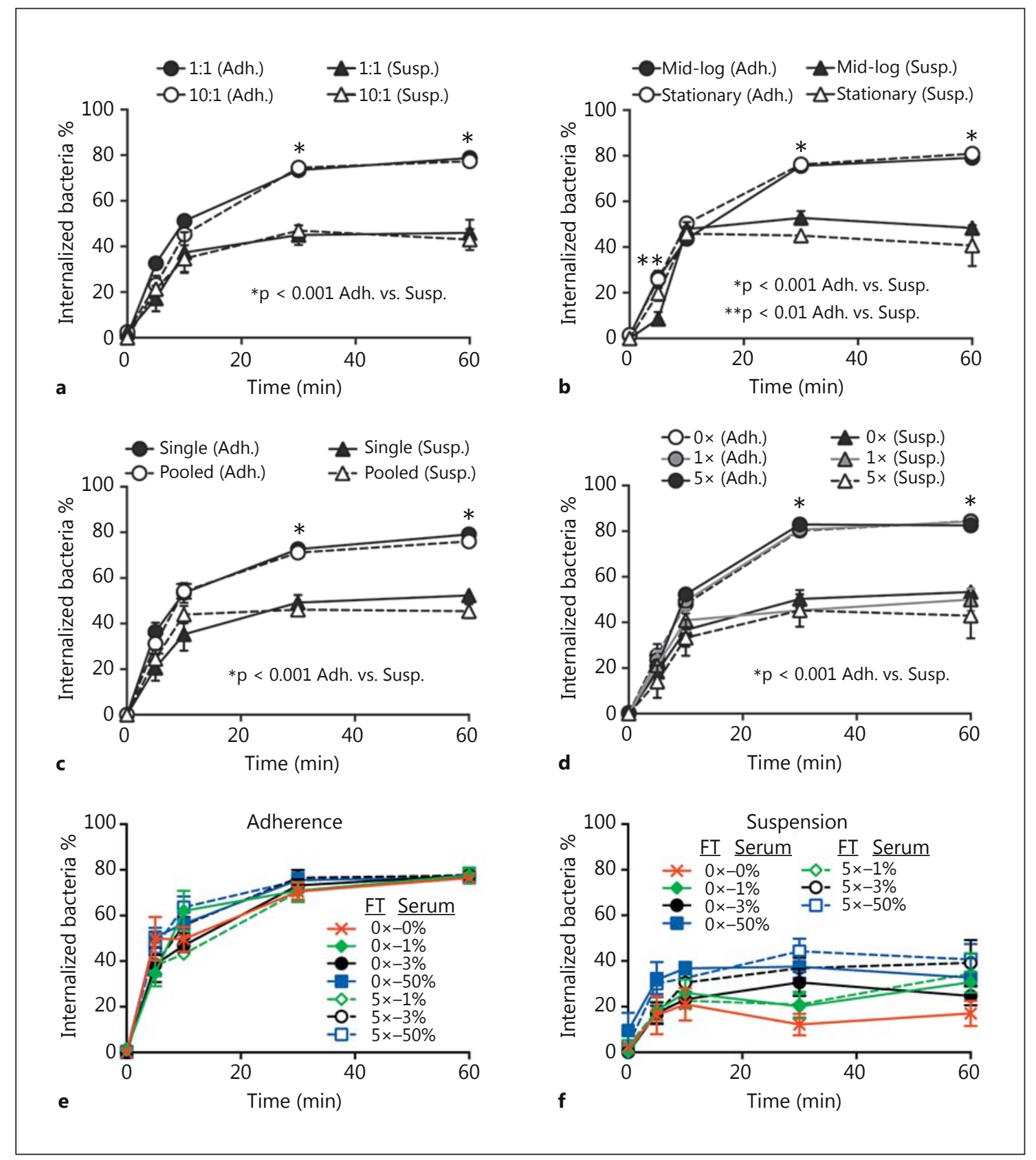

Fig. 1. Phagocytosis of $S$. aureus by human PMNs. a-d Adherent PMNs (Adh.) or those in suspension (Susp.) were incubated with $S$. aureus strain LAC and phagocytosis of bacteria was determined by fluorescence microscopy. Assays were performed using a CFU:PMN ratio of $1: 1$ or 10:1 (a), with LAC cultured to mid-logarithmic $\left(\mathrm{OD}_{600} \approx 0.7\right)$ or stationary phase $\left(\mathrm{OD}_{600} \approx 2.0\right)$ of growth (b), LAC opsonized with normal serum from 1 human donor (Sin- gle) or pooled from 5 donors (Pooled) (c), LAC opsonized with fresh normal human serum $(0 \times)$, serum freeze-thawed once $(1 \times)$ or five times $(5 \times)(\mathbf{d})$. Bacteria were opsonized with $50 \%$ serum $(\mathbf{d})$, or 0 (not opsonized), 1,3 or $50 \%$ serum as indicated $(\mathbf{e}, \mathbf{f})$. bf Assays were performed using a CFU:PMN ratio of 1:1. Data represent the mean of 5 independent experiments \pm SEM. ${ }^{*} \mathrm{p}<0.001$ PMN adherence vs. suspension assays. FT $=$ Freeze-thaw cycle. 

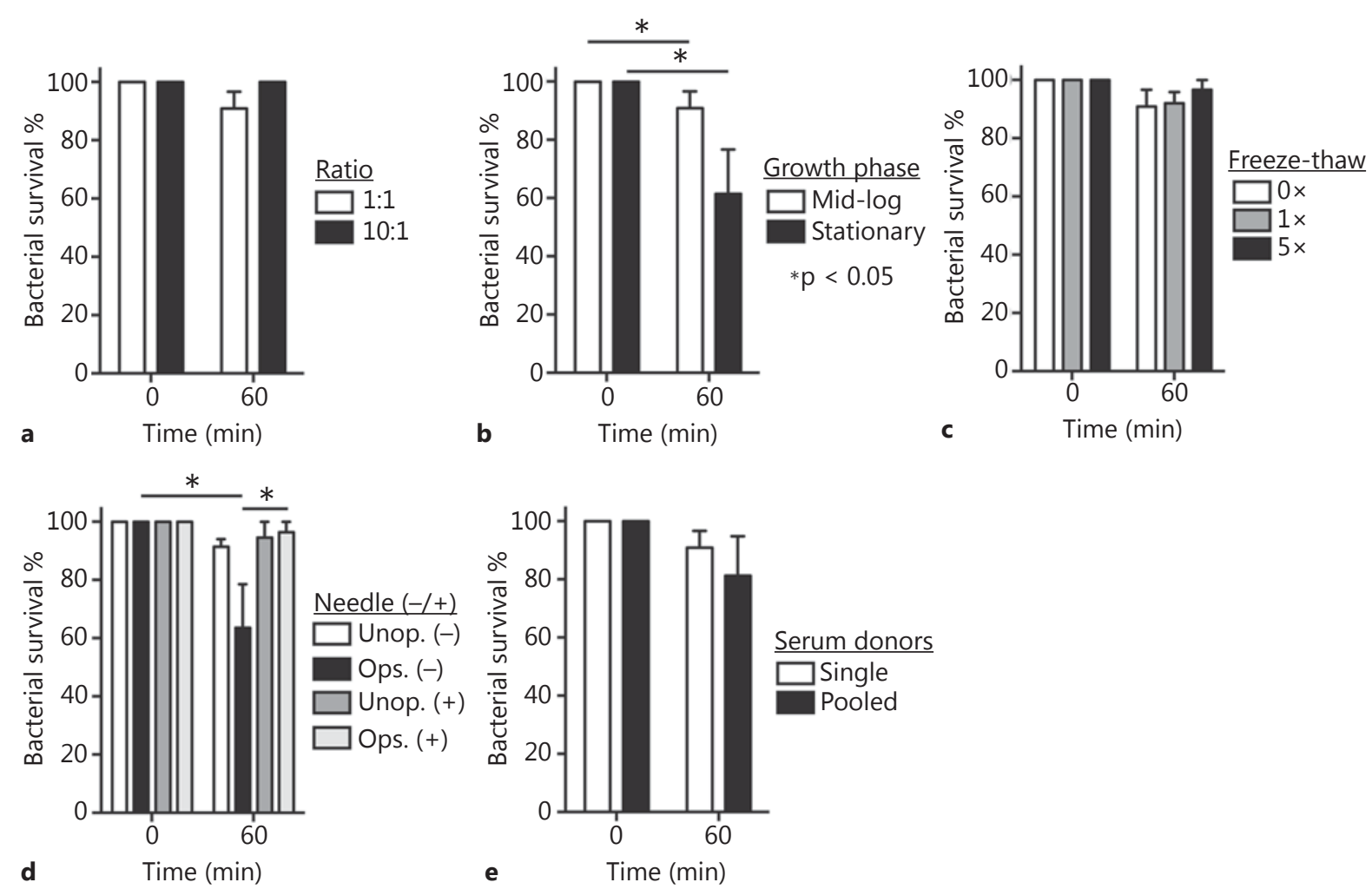

Fig. 2. Bactericidal activity of human $P M N$ toward $S$. aureus. a-e PMNs in suspension were incubated with $S$. aureus strain LAC and bactericidal activity was determined as described in the Methods. Assay conditions are identical to those described in the legend of figure 1. d Significant physical dispersion of bacterial clumps and cell aggregates by using a 25-gauge flat-end needle. Assays were performed using a CFU:PMN ratio of 1:1 unless indicated otherwise. Data represent the mean of 5 independent experiments \pm SEM. ${ }^{*} \mathrm{p}<0.05$. cytosis of S. aureus [7-9], only one of the conditions tested here influenced uptake of $S$. aureus by human neutrophils (see below; fig. 1). This finding is somewhat unexpected, since the repertoire and expression of $S$. aureus surface proteins that could impact phagocytosis are different at stationary and mid-exponential phases of growth. Moreover, multiple freeze-thaw cycles might be predicted to decrease effectiveness of serum opsonins, which, in turn, could impact phagocytosis [25]. Nonetheless, there was no difference in neutrophil uptake of $S$. aureus opsonized with fresh serum or serum that had been repeatedly frozen and thawed (fig. 1c, e, f).

In contrast, there was a significant difference in phagocytosis of $S$. aureus between neutrophils in suspension and those that were adherent (fig. 1). Approximately 40\% of the bacteria associated with the neutrophils in suspension were internalized by $10 \mathrm{~min}$, but this level of $S$. au- reus uptake did not increase significantly over time (for up to $60 \mathrm{~min}$ ). By comparison, the level of phagocytosis by adherent neutrophils increased over time (phagocytosis was $\sim 80 \%$ by $60 \mathrm{~min}$; fig. 1). The observation that more bacteria were ingested by adherent neutrophils compared with those in suspension is consistent with the idea that adherent neutrophils are 'primed' for enhanced phagocytosis, results also in accordance with previous studies [7-9].

\section{Bactericidal Activity of Neutrophils in Suspension}

We next determined if the phagocytosis results with neutrophils in suspension were mirrored by bactericidal activity. Although on average there was a difference in bacterial survival among some of the conditions tested, the differences were not statistically significant with a few exceptions (fig. 2). Notably, $\geq 80 \%$ of the initial S. aureus 
inoculum was recovered from all conditions tested except for bacteria cultured to the stationary phase of growth (recovery of CFUs was $61.5 \pm 15.2 \%$ ) and conditions in which cells were not dispersed by needle aspiration $(63.5$ $\pm 15.0 \%$ ). A number of previous studies have reported significant killing (range of $\sim 35-88 \%$ ) of S. aureus by neutrophils in suspension within $60 \mathrm{~min}$, albeit the assay conditions varied considerably [26-31]. Our initial results were consistent with these previous studies, but the reduction in CFUs was largely attributed to cell aggregation rather than killing of $S$. aureus, since aspiration and dispersion of samples with a 25 -gauge needle significantly increased the number of CFUs recovered (fig. 2d). Therefore, we used a 25-gauge needle to disaggregate all assay contents after solubilization in $1 \%$ saponin. Aggregation of $S$. aureus and neutrophils - especially serumopsonized S. aureus - in such assays is often not addressed and is a potential confounding factor that must be considered [32].

The apparent discordance between phagocytosis $(\sim 40-50 \%)$ and S. aureus survival $(\geq 80 \%)$ in suspension assays might be explained by at least two phenomena. First, uningested bacteria are not counted in phagocytosis assays but contribute to recovered CFUs in the survival assays. Second, a significant percentage of ingested S. aureus (30-50\% for strain LAC) are not killed by neutrophils $[15,31,33]$. In aggregate, these results suggest phagocytosis and killing of $S$. aureus by neutrophils in suspension - presumably akin to those in the bloodstream - are largely ineffective or inefficient under the conditions tested. That said, we previously demonstrated that neutrophils in human venous blood bind and/or ingest $S$. aureus, and that these bacteria ultimately cause neutrophil lysis [34]. The binding of $S$. aureus with PMNs in blood was verified here, as $>90 \%(92.6 \pm 1.4 \%)$ of neutrophils in human venous blood had bound and/or ingested $S$. aureus by $5 \mathrm{~min}$ (data not shown). These observations provide strong support to the idea that factors present in whole blood, likely molecules produced by other cell types or those in plasma, enhance neutrophil binding to S. aureus - conditions not fully reproduced by assays with purified neutrophils.

\section{Serum Opsonization and Neutrophil Phagocytosis}

It is well known that serum opsonins promote phagocytosis of $S$. aureus by neutrophils $[35,36]$. Indeed, binding and uptake of opsonized S. aureus by human neutrophils in suspension was significantly greater than that with unopsonized bacteria (e.g., association of $S$. aureus with neutrophils at $60 \mathrm{~min}$ was $62.5 \pm 4.4 \%$ for opsonized
S. aureus compared with $42.2 \pm 5.7 \%$ for unopsonized bacteria) (fig. 3a, b). In contrast, binding and phagocytosis of $S$. aureus was similar between opsonized and unopsonized adherent neutrophils (e.g., at $60 \mathrm{~min} 96.6 \pm 1.1 \%$ and $94.3 \pm 2.2 \%$ of adherent neutrophils were associated with opsonized and unopsonized $S$. aureus, respectively) (fig. 3a, b). These latter results were reflected in general by bacterial survival, since $S$. aureus survival was significantly reduced over time following phagocytosis by adherent neutrophils (serum opsonized or unopsonized) (fig. 3e). Collectively, these data indicate that serum opsonization of $S$. aureus enhances phagocytosis by neutrophils in suspension, which is consistent with previous work $[7,8]$, but has no apparent impact on binding or uptake of the pathogen by adherent neutrophils.

\section{Neutrophil Granule-Phagosome Fusion after}

Phagocytosis of S. aureus

We next determined whether the fusion of azurophilic granules with $S$. aureus phagosomes was enhanced by opsonization or neutrophil adherence. There was very similar - if not virtually identical - enrichment of CD63, a protein present in the membranes of azurophilic granules on phagosomes of adherent neutrophils following ingestion of opsonized or unopsonized USA300 (fig. 3f). Notably, $97-98 \%$ of these phagosomes were enriched with CD63 by $60 \mathrm{~min}$, indicating typical granule-phagosome fusion after ingestion of $S$. aureus. The findings are in accordance with our previous results using adherent neutrophils and serum opsonized S. aureus [15]. In contrast, there was limited enrichment of $S$. aureus phagosomes with CD63 by neutrophils in suspension and very little (or zero) with unopsonized bacteria (fig. 3f). These results suggest that granule-phagosome fusion and thus neutrophil activation is limited in suspension conditions following uptake of unopsonized S. aureus. This finding is perhaps not surprising, since different agonists have differential capacity to elicit neutrophil degranulation (e.g., see $[37,38]$ and more recently [39]), and activation by opsonized versus unopsonized bacteria proceeds in part through distinct receptors. These findings, coupled with limited phagocytosis by suspension neutrophils, provide an explanation in part for the high level of $S$. aureus survival under these assay conditions (compare fig. 3e and f).

\section{Anti-S. aureus $A b$ and Neutrophil Phagocytosis}

To determine whether uptake of opsonized $S$. aureus by neutrophils was mediated at least in part by specific $\mathrm{Ab}$, or if such $\mathrm{Ab}$ enhances uptake of $S$. aureus by neutrophils, we tested the ability of aS. aureus to promote opso- 


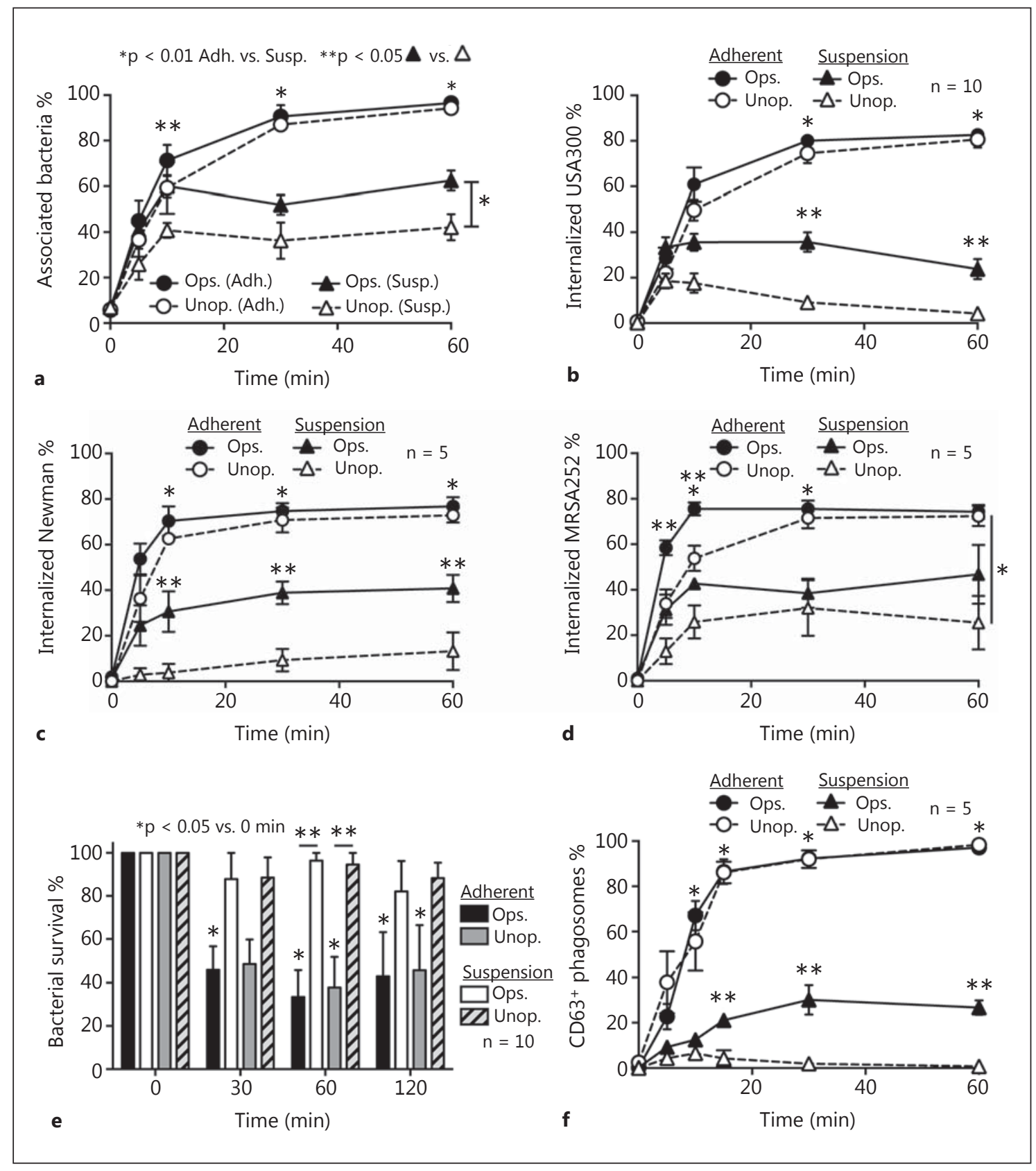

Fig. 3. Opsonization enhances uptake but not killing of $S$. aureus by human PMNs in suspension. a Percentage of PMNs associated with strain LAC was determined by light microscopy as described in the Methods. Phagocytosis (b-d) and bactericidal activity (e) of adherent PMNs (Adh.) or those in suspension (Susp.) were determined for opsonized (Ops.) and unopsonized S. aureus (Unop.). f CD63-enriched $S$. aureus phagosomes were assessed using fluo- rescence microscopy. Assays were performed using a CFU:PMN ratio of $1: 1$. Data represent the mean of 5 or 10 independent experiments \pm SEM as indicated. ${ }^{*} \mathrm{p}<0.05$ for phagocytosis using adherent PMNs vs. those in suspension using either opsonized or unopsonized bacteria. ${ }^{* *} \mathrm{p}<0.05$ for phagocytosis assays containing opsonized bacteria vs. unopsonized bacteria using either adherent PMNs or those in suspension. 
Fig. 4. Ab promotes phagocytosis of $S$. aureus. Phagocytosis (a) and bactericidal activity (b) of adherent PMNs were determined using opsonized (Ops.) and unopsonized (Unop.) S. aureus LAC (USA300) in the presence $(1: 1,000$ or $1: 100$ dilutions as indicated) or absence (none) of aS. $a u$ reus. Alternatively, PMNs in suspension were assessed for their ability to phagocytose (c) and kill (d) S. aureus. Assays were performed using a CFU:PMN ratio of $1: 1$. Data represent the mean of 5 independent experiments \pm SEM. ${ }^{*} \mathrm{p}<0.05$. NS $=$ Nonsignificant.

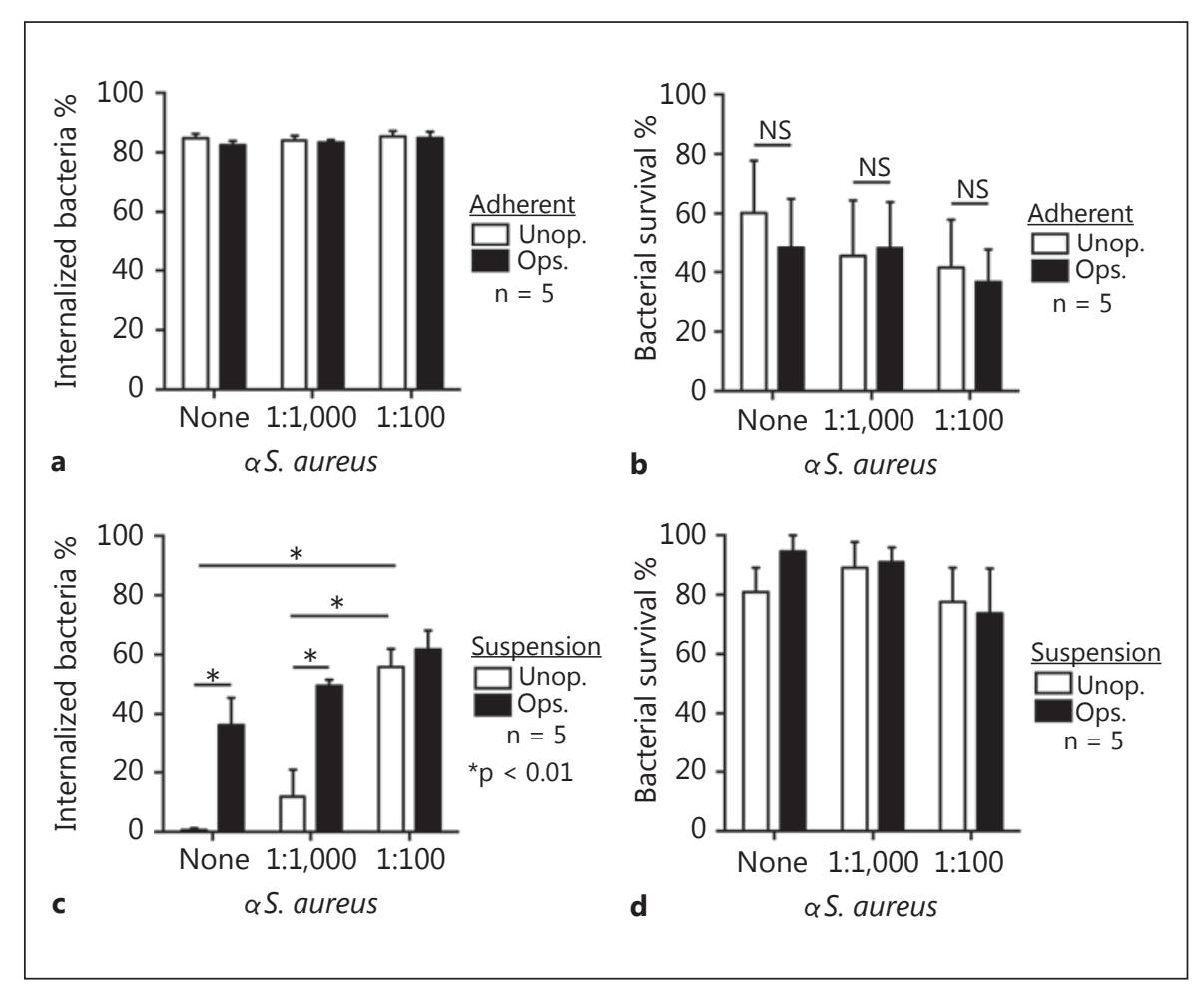

nophagocytosis. For these experiments, we used rabbit antiserum or purified rabbit IgG directed against 6 strains of heat-killed S. aureus (from two separate phases of growth) as described in the Methods. Notably, aS. aureus failed to enhance uptake by adherent neutrophils, which was $>80 \%$ within $1 \mathrm{~h}$ (and therefore near maximum) (fig. 4a). Consistent with this result, aS. aureus had no impact on killing of $S$. aureus by adherent neutrophils (fig. 4b).

In contrast, $a S$. aureus Ab significantly increased phagocytosis of $S$. aureus by neutrophils in suspension (e.g., uptake/internalization of bacteria increased from $0.7 \pm 0.7 \%$ in the absence of specific $\mathrm{Ab}$ at $60 \mathrm{~min}$ to 55.9 $\pm 6.1 \%$ with $\alpha$ S. aureus) (fig. $4 \mathrm{c}$ ). Although there was a trend towards increased uptake of human serum-opsonized S. aureus following addition of aS. aureus (e.g., uptake increased from $36.3 \pm 9.2 \%$ with no exogenous $\alpha S$. aureus added to $49.5 \pm 2.0$ and $61.8 \pm 6.3 \%$ using $1: 1,000$ and $1: 100$ dilutions of $\alpha S$. aureus, respectively), these results were not statistically significant. Moreover, the level of phagocytosis with bacteria opsonized with normal human serum alone $(36.3 \pm 9.2 \%)$ was not significantly different than that with unopsonized bacteria plus the highest concentration of aS. aureus (55.9 \pm $6.1 \%$ ) (fig. 4c).
Despite the enhanced $\alpha S$. aureus-mediated uptake of S. aureus by human neutrophils, there was no significant difference in bacterial survival in the presence or absence of aS. aureus (fig. $4 \mathrm{~d}$ ). The seeming inconsistencies with suspension phagocytosis (increased with specific $\mathrm{Ab}$ ) and $S$. aureus survival (no increase) are explained above (see text for fig. 2). The results with aS. aureus were mirrored by assays that contained IgG purified from rabbit antisera (aS. aureus) (fig. 5). These data suggest that the increased phagocytosis of $S$. aureus by suspension neutrophils in our assays was mediated primarily by $\mathrm{Ab}$ and not other factors present in serum (fig. 5). Taken together, these data provide evidence that $a S$. aureus has the capacity to enhance suspension phagocytosis under specific conditions.

\section{Discussion}

Whether humans develop immunity to $S$. aureus infections is an often-debated topic. On the one hand, the vast majority of individuals fail to develop serious or lifethreatening S. aureus infections during the course of their lifetime. This is perhaps remarkable, considering the high percentage of people who are permanently or intermit- 
Fig. 5. Purified $\mathrm{Ab}$ against $S$. aureus enhances uptake of bacteria. a, b aS. aureus or $a S$. aureus IgG purified from rabbit serum (25 $\mu \mathrm{g} / \mathrm{ml}$ final concentration) was added to phagocytosis $(\mathbf{a}, \mathbf{b})$ or bactericidal activity (c) assays containing PMNs in suspension. The assays contained unopsonized $S$. aureus (Unop.) or serum opsonized bacteria (Ops.) as indicated. Assays were performed using a CFU:PMN ratio of $1: 1$. Data represent the mean of 5 independent experiments \pm SEM. ${ }^{*} \mathrm{p}<0.05$. NS $=$ Nonsignificant.

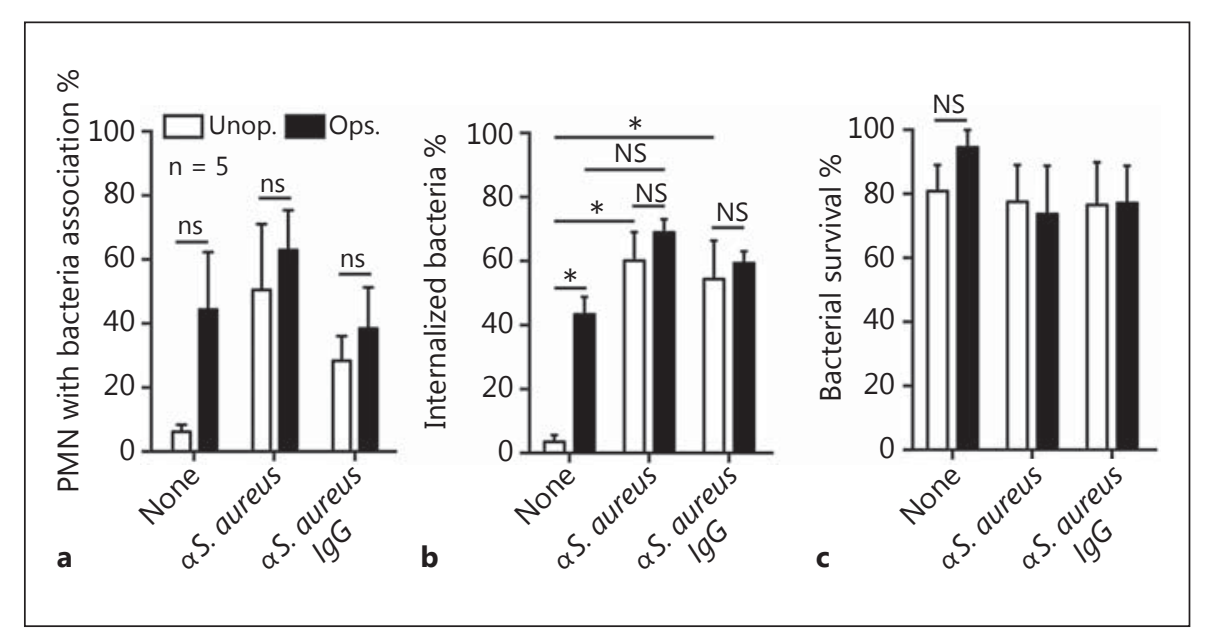

tently colonized with $S$. aureus [40]. On the other hand, there is a relative high abundance of invasive $S$. aureus/ MRSA infections in health care facilities, and some individuals develop recurrent infections. One explanation for these infections is that the individuals have risk factors for infection, such as indwelling medical devices or immune suppression [41]. Thus, they lack competent innate immunity and/or they fail to develop adaptive immunity to S. aureus. Inasmuch as neutrophil phagocytosis and killing of bacteria are critical for host defense - especially against $S$. aureus - enhancing these functions would be an important step forward in our efforts to develop new therapies to treat infections. Indeed, there have been several recent efforts to develop a vaccine that promotes opsonophagocytosis of $S$. aureus, but none has been successful in human clinical trials. To better understand the disconnect between positive outcomes in pre-clinical studies and negative outcomes in human clinical trials, we investigated conditions in vitro that are optimal for phagocytosis and killing of $S$. aureus by human neutrophils. It is important to note that vaccine approaches directed to enhance opsonophagocytosis are distinct from those directed to neutralize secreted $S$. aureus molecules such as cytolytic toxins or enterotoxins. Thus, our data bear only on opsonophagocytosis approaches.

Notably, we found that phagocytosis and killing of USA300 by adherent neutrophils was comparable (and rapid) for serum opsonized or unopsonized bacteria. These findings seem at variance with the notion that specific $\mathrm{Ab}$ is required for efficient uptake of $S$. aureus by neutrophils. However, it is well known that neutrophils primed by adherence have enhanced functions, including phagocytosis [42], a phenomenon that likely explains the

Phagocytosis and Killing of S. aureus by Human Neutrophils rapid uptake of $S$. aureus in the absence of host opsonins. It is also known that phagocytosis of unopsonized $S$. aureus can proceed through a number of previously described receptor pathways, including those involving lectin, protein, or hydrophobic interactions [43]. An implication of these findings is that an approach to enhance opsonophagocytosis will be ineffective for infections in which neutrophils are adherent - e.g., skin and soft tissue infections.

In contrast, opsonization of $S$. aureus with human serum enhanced phagocytosis by neutrophils in suspension, findings that corresponded with increased granulephagosome fusion using these conditions (fig. 3). These findings are consistent with previous studies that have demonstrated the ability of normal human serum, which includes IgG and complement, to promote phagocytosis in suspension [7, 8]. Despite this observation, there was weak correlation between uptake of $S$. aureus and subsequent killing of bacteria by neutrophils in suspension (fig. 3). Such disparity may be inherent to the assay readouts, since the bactericidal activity assay measures viable bacteria (inside or outside of neutrophils), whereas the phagocytosis assay evaluates only those bound and/or ingested by neutrophils.

In addition to priming by adherence as discussed above, a key difference between assays with adherent neutrophils and those containing neutrophils in suspension is with the kinetics of phagocytosis. For assays with adherent neutrophils, phagocytosis is synchronized and the majority of bacteria are internalized within the first 30 min after the start of the assay. In contrast, phagocytosis of bacteria in suspension is asynchronous, and some bacteria will be taken up at different time points over the 
course of the assay period. Such a phenomenon may also contribute to the noted difference in bactericidal activity between the two types of assays.

In accordance with previous in vitro studies, we found that $\mathrm{Ab}$ specific for $S$. aureus enhanced uptake of unopsonized bacteria and, at the highest Ab concentration, to the level of ingestion conferred by normal human serum [44-48]. However, anti-S. aureus Ab failed to increase phagocytosis of serum-opsonized S. aureus significantly, although there was a trend to increased uptake (fig. 4c, 5a). Collectively, these findings indicate that Ab specific for $S$. aureus promotes phagocytosis under defined circumstances (suspension in the absence of serum opso- nins), but the additive contribution of such $\mathrm{Ab}$ is limited for phagocytosis in human serum. These findings should be considered as the field moves forward in an effort to develop a vaccine designed to moderate or prevent $S$. aureus infections.

\section{Acknowledgments}

We thank Brett Freedman and Ashley Schrammeck for assistance with phagocytosis and bactericidal activity assays. This research was supported by the Intramural Research Program of the National Institute of Allergy and Infectious Diseases, National Institutes of Health.

\section{References}

1 Lee WL, Harrison RE, Grinstein S: Phagocytosis by neutrophils. Microbes Infect 2003;5: 1299-1306.

2 Nordenfelt P, Tapper H: Phagosome dynamics during phagocytosis by neutrophils. J Leukoc Biol 2011;90:271-284.

3 Rigby K, DeLeo F: Neutrophils in innate host defense against Staphylococcus aureus infections. Semin Immunopathol 2012;34:237-259.

-4 Diekema DJ, Pfaller MA, Schmitz FJ, Smayevsky J, Bell J, Jones RN, Beach M: Survey of infections due to Staphylococcus species: frequency of occurrence and antimicrobial susceptibility of isolates collected in the United States, Canada, Latin America, Europe, and the Western Pacific region for the SENTRY Antimicrobial Surveillance Program, 1997-1999. Clin Infect Dis 2001; 32:S114-S132.

5 DeLeo F, Chambers H: Reemergence of antibiotic-resistant Staphylococcus aureus in the genomics era. J Clin Invest 2009;119:24642474.

6 Wright AE, Douglas SR, John Burdon S: An experimental investigation of the role of the blood fluids in connection with phagocytosis. Rev Infect Dis 1989;11:827-834.

7 Verhoef J, Peterson P, Kim Y, Sabath LD, Quie PG: Opsonic requirements for staphylococcal phagocytosis. Heterogeneity among strains. Immunology 1977;33:191-197.

8 Verbrugh HA, Van Dijk WC, Peters R, Van Der Tol ME, Peterson PK, Verhoef J: Staphylococcus aureus opsonization mediated via the classical and alternative complement pathways. A kinetic study using MgEGTA chelated serum and human sera deficient in IgG and complement factors $\mathrm{C} 1 \mathrm{~s}$ and $\mathrm{C} 2$. Immunology 1979;36:391-397.

-9 Vandenbroucke Grauls CM, Thijssen HM, Verhoef J: Interaction between human polymorphonuclear leucocytes and Staphylococcus aureus in the presence and absence of opsonins. Immunology 1984;52:427-435.
10 Kennedy A, Willment J, Dorward D, Williams D, Brown G, DeLeo F: Dectin-1 promotes fungicidal activity of human neutrophils. Eur J Immunol 2007;37:467-478.

11 Nauseef WM, Clark RA: Granulocytic Phagocytes. New York, Elsevier/Churchill Livingstone, 2010

12 Fattom AI, Naso R: Staphylococcal vaccines: a realistic dream. Ann Med 1996;28:43-46.

13 Jansen KU, Girgenti DQ, Scully IL, Anderson AS: Vaccine review: 'Staphyloccocus aureus vaccines: problems and prospects'. Vaccine 2013;31:2723-2730.

14 Spellberg B, Daum R: Development of a vaccine against Staphylococcus aureus. Semin Immunopathol 2012;34:335-348.

15 Voyich J, Braughton K, Sturdevant D, Whitney A, Sad-Salim B, Porcella S, Long RD, Dorward D, Gardner D, Kreiswirth B, Musser J, DeLeo F: Insights into mechanisms used by Staphylococcus aureus to avoid destruction by human neutrophils. J Immunol 2005; 175 : 3907-3919.

16 Diep BA, Gill SR, Chang RF, Phan TH, Chen JH, Davidson MG, Lin F, Lin J, Carleton HA, Mongodin EF, Sensabaugh GF, PerdreauRemington F: Complete genome sequence of USA300, an epidemic clone of communityacquired meticillin-resistant Staphylococcus aureus. Lancet 2006;367:731-739.

17 Baba T, Takeuchi F, Kuroda M, Yuzawa H, Aoki K, Oguchi A, Nagai Y, Iwama N, Asano K, Naimi T, Kuroda H, Cui L, Yamamoto K, Hiramatsu K: Genome and virulence determinants of high virulence communityacquired MRSA. Lancet 2002;359:18191827.

18 Holden MTG, Feil EJ, Lindsay JA, Peacock SJ, Day NPJ, Enright MC, Foster TJ, Moore CE, Hurst L, Atkin R, Barron A, Bason N, Bentley SD, Chillingworth C, Chillingworth T, Churcher C, Clark L, Corton C, Cronin A, Doggett J, Dowd L, Feltwell T, Hance Z, Harris B, Hauser H, Holroyd S, Jagels K,
James KD, Lennard N, Line A, Mayes R, Moule S, Mungall K, Ormond D, Quail MA, Rabbinowitsch E, Rutherford K, Sanders M, Sharp S, Simmonds M, Stevens K, Whitehead S, Barrell BG, Spratt BG, Parkhill J: Complete genomes of two clinical Staphylococcus aureus strains: evidence for the rapid evolution of virulence and drug resistance. Proc Natl Acad Sci USA 2004;101:97869791.

19 Baba T, Bae T, Schneewind O, Takeuchi F, Hiramatsu K: Genome sequence of Staphylococcus aureus strain Newman and comparative analysis of staphylococcal genomes: polymorphism and evolution of two major pathogenicity islands. J Bacteriol 2008;190: 300-310.

20 Gill SR, Fouts DE, Archer GL, Mongodin EF, DeBoy RT, Ravel J, Paulsen IT, Kolonay JF, Brinkac L, Beanan M, Dodson RJ, Daugherty SC, Madupu R, Angiuoli SV, Durkin AS, Haft DH, Vamathevan J, Khouri H, Utterback T, Lee C, Dimitrov G, Jiang L, Qin H, Weidman J, Tran K, Kang K, Hance IR, Nelson KE, Fraser CM: Insights on evolution of virulence and resistance from the complete genome analysis of an early methicillin-resistant Staphylococcus aureus strain and a biofilmproducing methicillin-resistant Staphylococcus epidermidis strain. J Bacteriol 2005;187: 2426-2438.

- 21 Kuroda M, Ohta T, Uchiyama I, Baba T, Yuzawa H, Kobayashi I, Cui L, Oguchi A, Aoki K, Nagai Y, Lian J, Ito T, Kanamori M, Matsumaru $\mathrm{H}$, Maruyama A, Murakami H, Hosoyama A, Mizutani-Ui Y, Takahashi NK, Sawano T, Inoue R, Kaito C, Sekimizu K, Hirakawa $\mathrm{H}$, Kuhara $\mathrm{S}$, Goto S, Yabuzaki J, Kanehisa M, Yamashita A, Oshima K, Furuya K, Yoshino C, Shiba T, Hattori M, Ogasawara N, Hayashi H, Hiramatsu K: Whole genome sequencing of meticillin-resistant Staphylococcus aureus. Lancet 2001;357: 1225-1240. 
-22 Kobayashi S, Voyich J, Buhl C, Stahl R, DeLeo $\mathrm{F}$ : Global changes in gene expression by human polymorphonuclear leukocytes during receptor-mediated phagocytosis: cell fate is regulated at the level of gene expression. Proc Natl Acad Sci USA 2002;99:6901-6906.

-23 DeLeo FR, Allen L-AH, Apicella M, Nauseef WM: NADPH oxidase activation and assembly during phagocytosis. J Immunol 1999; 163:6732-6740.

24 Kobayashi S, Braughton K, Whitney A, Voyich J, Schwan T, Musser J, DeLeo F: Bacterial pathogens modulate an apoptosis differentiation program in human neutrophils. Proc Natl Acad Sci USA 2003;100:10948-10953.

25 DiMagno EP, Corle D, O’Brien JF, Masnyk IJ, Go VL, Aamodt R: Effect of long-term freezer storage, thawing, and refreezing on selected constituents of serum. Mayo Clin Proc 1989; 64:1226-1234.

26 Decleva E, Menegazzi R, Busetto S, Patriarca P, Dri P: Common methodology is inadequate for studies on the microbicidal activity of neutrophils. J Leukoc Biol 2006;79: 87-94.

-27 Collins LV, Kristian SA, Weidenmaier C, Faigle M, van Kessel KPM, van Strijp JAG, Götz F, Neumeister B, Peschel A: Staphylococcus aureus strains lacking D-alanine modifications of teichoic acids are highly susceptible to human neutrophil killing and are virulence attenuated in mice. J Infect Dis 2002;186:214219.

28 Wilsson A, Lundqvist H, Gustafsson M, Stendahl O: Killing of phagocytosed Staphylococcus aureus by human neutrophils requires intracellular free calcium. J Leukoc Biol 1996; 59:902-907.

29 Hunt CL, Nauseef WM, Weiss JP: Effect of Dalanylation of (lipo)teichoic acids of Staphylococcus aureus on host secretory phospholipase A2 action before and after phagocytosis by human neutrophils. J Immunol 2006;176: 4987-4994.
30 Verbrugh HA, Peters R, Peterson PK, Verhoef $\mathrm{J}$ : Phagocytosis and killing of staphylococci by human polymorphonuclear and mononuclear leucocytes. J Clin Pathol 1978;31:539-545.

31 Rogers DE, Tompsett R: The survival of staphylococci within human leukocytes. J Exp Med 1952;95:209-230.

32 Dugger KO, Galgiani JN: Neutrophil killing of single microorganisms as measured by a new method. Diagn Microbiol Infect Dis 1989;12:199-203.

33 Kobayashi S, Braughton K, Palazzolo Ballance A, Kennedy A, Sampaio E, Kristosturyan E, Whitney A, Sturdevant D, Dorward D, Holland S, Kreiswirth B, Musser J, DeLeo F: Rapid neutrophil destruction following phagocytosis of Staphylococcus aureus. J Innate Immun 2010;2:560-575.

34 Malachowa N, Whitney AR, Kobayashi SD, Sturdevant DE, Kennedy AD, Braughton KR, Shabb DW, Diep BA, Chambers HF, Otto M, DeLeo FR: Global changes in Staphylococcus aureus gene expression in human blood. PLoS One 2011;6:e18617.

35 Rogers DE, Melly MA: Observations on the immunology of pathogenic staphylococci. Yale J Biol Med 1962;34:560-581.

36 Cohn ZA, Morse SI: Interactions between rabbit polymorphonuclear leucocytes and staphylococci. J Exp Med 1959;110:419-443.

37 Leffell MS, Spitznagel JK: Intracellular and extracellular degranulation of human polymorphonuclear azurophil and specific granules induced by immune complexes. Infect Immun 1974;10:1241-1249.

- 38 Densen P, Mandell GL: Gonococcal interactions with polymorphonuclear neutrophils: importance of the phagosome for bactericidal activity. J Clin Invest 1978;62:1161-1171.

39 Bellocchio S, Moretti S, Perruccio K, Fallarino F, Bozza S, Montagnoli C, Mosci P, Lipford GB, Pitzurra L, Romani L: TLRs govern neutrophil activity in aspergillosis. J Immunol 2004;173:7406-7415.
40 Kluytmans J, van Belkum A, Verbrugh $\mathrm{H}: \mathrm{Na}-$ sal carriage of Staphylococcus aureus: epidemiology, underlying mechanisms, and associated risks. Clin Microbiol Rev 1997;10:505520.

41 Lowy FD: Staphylococcus aureus infections. N Engl J Med 1998;339:520-532.

42 Wood WB, Smith MR, Watson B: Studies on the mechanism of recovery in pneumococcal pneumonia: IV. The mechanism of phagocytosis in the absence of antibody. J Exp Med 1946;84:387-402.

43 Ofek I, Goldhar J, Keisari Y, Sharon N: Nonopsonic phagocytosis of microorganisms. Annu Rev Microbiol 1995;49:239-276.

44 Jung D-J, An J-H, Kurokawa K, Jung Y-C, Kim M-J, Aoyagi Y, Matsushita M, Takahashi S, Lee H-S, Takahashi K, Lee B: Specific serum Ig recognizing staphylococcal wall teichoic acid induces complement-mediated opsonophagocytosis against Staphylococcus aureus. J Immunol 2012;189:4951-4959.

45 Theilacker C, Kropec A, Hammer F, Sava I Wobser D, Sakinc T, Codée JDC, Hogendorf WFJ, van der Marel GA, Huebner J: Protection against Staphylococcus aureus by antibody to the polyglycerolphosphate backbone of heterologous lipoteichoic acid. J Infect Dis 2012;205:1076-1085.

46 Ebert T, Smith S, Pancari G, Clark D, Hampton R, Secore S, Towne V, Fan H, Wang X-M, Wu X, Ernst R, Harvey BR, Finnefrock AC, Wang F, Tan C, Durr E, Cope L, Anderson A, An Z, McNeely T: A fully human monoclonal antibody to Staphylococcus aureus iron regulated surface determinant B (IsdB) with functional activity in vitro and in vivo. Hum Antibodies 2010;19:113-128.

47 Kobayashi SD, DeLeo FR: A MRSA-terious enemy among us: boosting MRSA vaccines. Nat Med 2011;17:168-169.

48 Gordon DL, Rice JL: Opsonin-dependent and independent surface phagocytosis of $S$. aureus proceeds independently of complement and complement receptors. Immunology 1988; 64:709-714.
Phagocytosis and Killing of S. aureus by Human Neutrophils
J Innate Immun 2014;6:639-649 